\title{
Analysis of trace atrazine and simazine in environmental samples by liquid chromatography-fluorescence detection with pre-column derivatization reaction
}

\author{
Aijun Gong, Changming Ye* \\ Research Center for Eco-Environmental Sciences, Chinese Academy of Sciences, P.O. Box 2871, Beijing 100085, China
}

Received 3 March 1998; received in revised form 15 September 1998; accepted 15 September 1998

\begin{abstract}
Coupled with off-line extraction, a pre-column derivatization liquid chromatographic fluorescence detection (LC-FL) procedure was developed for the determination of atrazine and simazine in soil, crop and water samples. Concentrations in real samples were expected to be at or below the low $\mathrm{ng} / \mathrm{g}$ level, which requires pre-concentration of analytes and improved detection. 4-(2-Phthalimidyl) benzoyl chloride (PIB-Cl) was used as a pre-column derivatization reagent for highperformance liquid chromatography. The clean-up and second-time concentration procedures, which were indispensable in the conventional analytical methods for soil and crop analysis because of the complexity of the samples, were replaced by a derivatization reaction between PIB-Cl and the analytes. The fluorescent and ultraviolet characteristics of the derivatives were investigated. The derivatization reaction and chromatographic separation conditions were optimized systematically. Detection limits of $1.2 \mathrm{ng} / \mathrm{g}$ for atrazine and $1.1 \mathrm{ng} / \mathrm{g}$ for simazine were obtained with recoveries of $84-95 \%$ for environmental samples. On the basis of practical application to five soil and five crop samples, the LC-FL method was compared with the conventional GC-MS method. (C) 1998 Elsevier Science B.V. All rights reserved.
\end{abstract}

Keywords: Environmental analysis; Water analysis; Soil; Derivatization, LC; Atrazine; Simazine; Phthalimidylbenzoyl chloride; Pesticides

\section{Introduction}

Atrazine and simazine are mainly released into the environment by agricultural and industrial processes. As a result, these contaminants end up in soil, crop and water. In order to detect them at the very low levels encountered in real samples, many analytical methods were developed [1-4]. In recent years, several procedures, including the on-line combination of solid-phase extraction (SPE)-liquid chroma-

\footnotetext{
*Corresponding author. Tel: +86 1062925511 3207, Fax: +86

10 62923563, E-mail: gongaij@mail.rcees.ac.cn
}

tography (LC)-mass spectrometry (MS) [5,6], SPELC-diode array detection (DAD) [7] and SPE-gas chromatography (GC)-MS [8], the use of largevolume injection in GC-cryotrapping-Fourier transform infrared spectrometry (FT-IR) [9] or GC-MSMS [10] and the application of new lamina extraction disks [11], have successfully been applied for the identification and quantitation of atrazine and simazine in surface, ground and drinking water. Detection limits at the $\mu \mathrm{g} / \mathrm{l}$, even $\mathrm{ng} / \mathrm{l}$ levels, could be obtained. Less often, works however, have been found to improve the analytical methods of atrazine and simazine in soil and crop samples because of the 
complexity of these samples. The enzyme-immunoassay of atrazine and simazine was also mainly developed for water samples [12-14]. Difficulty in optimizing the extraction conditions when strong interactions occur between the analytes and the matrix was found for the supercritical fluid extraction (SFE) technique used for real soil samples analysis [15].

The pre-column derivatization LC-fluorescence detection (FL) technique, from another point of view, was developed to improve the analytical method. In this paper a derivatization reagent, 4-(2phthalimidyl)benzoyl chloride (PIB-Cl), was applied to react with atrazine and simazine for their determination. There were four characteristics for the off-line pre-column derivatization LC-FL method. The first aspect was fluorescence detection, i.e., to increase the sensitivity of the analytes. The fluorescent investigation indicated that atrazine and simazine have no fluorescent properties but their PIB-Cl derivatives have strong fluorescent characteristics. Detection limits at the $\mu \mathrm{g} / \mathrm{g}$ level can be obtained not only for water samples but also for soil and crop samples. The second aspect is to omit the clean-up and second-time concentration processes. A lot of co-extracts from soil and crop samples are no longer identified by fluorescent detection. Therefore, the time-consuming clean-up and second-time concentration procedures could be omitted. The third aspect is that by using off-line extraction, larger amounts of soil and crop samples can be extracted if necessary in order to acquire the low detection limits. Finally, under the derivatization and detection conditions mentioned in this paper, only atrazine and simazine can be determined. The other triazine which contains $-\mathrm{NH}$ group(s) can be detected if the excitation and emission wavelength are adjusted for them. In brief, the complicated soil and crop samples can be analyzed and the low detection limits at $\mathrm{ng} / \mathrm{g}$ levels can be obtained by taking advantage of the high sensitivity and selectivity that can be achieved by fluorescence detection.

In our laboratory, the derivative reaction and chromatographic separation conditions for atrazine and simazine were investigated and optimized. The repeatability, precision and recovery of this method were examined. The analytical data of five agricultural soil and five crop samples, analyzed by this method, were compared with the conventional GCMS method.

The study demonstrated that the off-line pre-column derivatization LC-FL method was an alternative to the conventional GC-MS or GC-nitrogenphosphorous detection (NPD) methods for the determination of atrazine and simazine in the real samples, especially in soil and crop samples.

\section{Experimental}

\subsection{Apparatus and materials}

The high-performance liquid chromatography (HPLC) measurements were carried out on a Shimadzu LC-6A instrument equipped with Shimadzu fluorescence spectromonitor RF-510LC detector. The stainless steel column used $(25 \mathrm{~cm} \times$ 4.6 mm I.D.) was packed with DuPont ODS chemically bonded phase, particle size $10 \mu \mathrm{m}$, and was pre-tested by the manufacturer. The excitation wavelength of $312 \mathrm{~nm}$ and emission wavelength of 420 $\mathrm{nm}$ were selected for all measurements. The derivatives were eluted with methanol- water $(73: 27, \mathrm{v} / \mathrm{v}$, $\mathrm{pH} \mathrm{6)}$ at a flow-rate of $0.8 \mathrm{ml} / \mathrm{min}$.

Atrazine and simazine were purchased from CibaGeigy (Basel, Switzerland). PIB-Cl was synthesized using a literature method [16]. A Milli-Q pure water device was used. All organic solvents were of analytical-reagent grade and purified by redistillation.

Soil samples from an agricultural area (Hebei Province, China) were collected from the surface (top $10 \mathrm{~cm}$ ), freeze-dried and sieved through a $120-\mu \mathrm{m}$ mesh. The composition of the soil is shown in Table 1. For crop analysis the died whole rice plants were collected from a atrazine-accident field (Hebei Province, China), freeze-dried and sieved

Table 1

The composition of the soil samples

\begin{tabular}{lrllll}
\hline & Clay $(\%)$ & Silt $(\%)$ & Sand $(\%)$ & Organic carbon $(\%)$ & $\mathrm{pH}$ \\
\hline 1 & 7 & 30 & 63 & 1.8 & 7.8 \\
2 & 12 & 35 & 53 & 1.4 & 8.1 \\
3 & 5 & 22 & 73 & 0.8 & 7.7 \\
4 & 10 & 40 & 50 & 2.3 & 7.5 \\
5 & 8 & 25 & 67 & 2.0 & 7.3 \\
\hline
\end{tabular}


through a $120-\mu \mathrm{m}$ mesh. Water samples from industrial waste water were collected in a clear glass bottle and adjusted to $\mathrm{pH}$ 6, then filtered with a microporous funnel (4G).

\subsection{Synthesis of $\mathrm{PIB}-\mathrm{Cl}$}

PIB-Cl was synthesized with $o$-phthalaldehyde and 4-aminobenzoic acid using a literature method [16] and examined by MS [PIB-Cl, fine colourless needles, m.p. $>230^{\circ} \mathrm{C}$. Calc. for $\mathrm{C}_{15} \mathrm{H}_{10} \mathrm{NO}_{2} \mathrm{Cl}$ : $66.4 \% \mathrm{C}, 3.7 \% \mathrm{H}, 5.2 \% \mathrm{~N}$; found: $66.6 \% \mathrm{C}, 3.8 \% \mathrm{H}$, $5.2 \% \mathrm{~N}$. MS $\mathrm{m} / \mathrm{z}, 271(\mathrm{M}+)]$ and by IR $\left[740 \mathrm{~cm}^{-1}\right.$ $\mathrm{C}-\mathrm{Cl}, 1300 \mathrm{~cm}^{-1} 1370 \mathrm{~cm}^{-1} \mathrm{C}-\mathrm{N}, 1600 \mathrm{~cm}^{-1}$ $\left.\mathrm{C}_{6} \mathrm{H}_{6}, 1690 \mathrm{~cm}^{-1} \mathrm{C}=\mathrm{O}\right]$.

The examination showed that the synthesized product $\mathrm{PIB}-\mathrm{Cl}$ was in good agreement with its molecular formula and structure.

\subsection{Method}

One hundred grams of soil sample and $100.0 \mathrm{ml}$ of methanol were added to a 300.0-ml plug-Erlenmeyer flask. The mixture was shaken for $1.5 \mathrm{~h}$ at $270 \mathrm{rpm}$ on an oscillating machine. The soil extract was prepared for further treatment.

One hundred grams of crop sample and $100.0 \mathrm{ml}$ of methanol were added to a 300-ml plug-Erlenmeyer flask. The mixture was immersed for $12 \mathrm{~h}$ at room temperature and shaken for $2.0 \mathrm{~h}$ at $270 \mathrm{rpm}$ on an oscillating machine. The crop extract was prepared for further treatment.

Two hundred millilitres of water sample, $20 \mathrm{ml}$ of acetone, $5 \mathrm{~g}$ of sodium chloride, and $50 \mathrm{ml}$ of methylene chloride were added to a $500-\mathrm{ml}$ bottle. The mixture was stirred for 30 min using a PTFEcoated stirring bar. The content was transferred to a 1-1 separatory funnel. The organic layer was drained into a 500-ml roundbottom flask and the aqueous layer was returned back to the original sample bottle. Extraction was repeated twice. The water extract was prepared for further treatment.

Under reduced pressure, water, soil and crop extracts were filtered with a microporous funnel (4G) and through $5 \mathrm{~cm}$ of anhydrous $\mathrm{Na}_{2} \mathrm{SO}_{4}$ in a sintered glass filter column. A 50-ml volume of fresh methylene chloride was used for washing the column. The extracts were evaporated to about $3 \mathrm{ml}$ on a rotary evaporator at $35^{\circ} \mathrm{C}$ in a water bath with vacuum. The concentrated extracts were dried under a gentle stream of nitrogen. They were transferred to a flask and diluted to $5.0 \mathrm{ml}$ with benzene quantitatively.

A 4.0-ml sample extract was collected in a $25-\mathrm{ml}$ plug-Erlenmeyer flask. Six milligrams of PIB-Cl and $1.0 \mathrm{~g}$ of catalyst were added to the flask. The mixture was shaken gently for $25 \mathrm{~min}$ at $20^{\circ} \mathrm{C}$ in a water bath and centrifuged at $4000 \mathrm{rpm}$. Then, $5 \mu \mathrm{l}$ of clear liquid was injected onto the column.

\section{Results and discussion}

\subsection{Optimization of derivatization conditions}

A systematic study of the conditions for derivatization was performed with temperature being varied between 0 and $40^{\circ} \mathrm{C}$ and the reaction time between $20 \mathrm{~min}$ and $60 \mathrm{~h}$. The optimum conditions were a reaction time of $25 \mathrm{~min}$ at $20^{\circ} \mathrm{C}$.

A mixture of the solid $\mathrm{NaOH}-\mathrm{Na}_{2} \mathrm{CO}_{3}(1: 1, \mathrm{w} / \mathrm{w}$, 80 mesh) was prepared as the catalyst for the derivatization reaction. The maximum yield was achieved when the mole ratios of $\mathrm{PIB}-\mathrm{Cl}$ to atrazine and simazine were $>3$ and the catalyst to atrazine and simazine ratio was $>3800$. In order to ensure the maximum yield, $6.0 \mathrm{mg} \mathrm{PIB}-\mathrm{Cl}$ (PIB-Cl/analytes more than 10) was applied to the analytes at the $\mu \mathrm{g} / \mathrm{g}$ level for every derivatization procedure.

For the derivatization reaction, acetone, acetonitrile, methylene chloride, tretramethylene oxide and benzene were tested. Benzene, treated with sodium metal to remove the trace water, was the best solvent because of the high solubility of reactants and derivatives. Benzene was also a safe solvent for the chromatographic column because of the very low solubility of the catalyst in it. Moreover, the derivatives were stable for more than 10 days if kept in benzene at room temperature.

\subsection{Chromatographic conditions}

The derivatives were scanned using a Shimadzu DU-650 spectrophotometer and RF-520 spectrofluorophotometer. The ultraviolet absorption wavelength of $345 \mathrm{~nm}$ and strong blue fluorescent charac- 
teristics for the derivatives were found. The optimum excitation and emission wavelengths were $312 \mathrm{~nm}$ and $420 \mathrm{~nm}$, respectively.

Aqueous acetonitrile, methanol and tretramethylene oxide were tested for the chromatographic separation. Aqueous methanol was found to be the optimum mobile phase for the separation and determination of the derivatives.

The separation of derivatives was carried out on a ODS chemically bonded phase column with watermethanol. For standard samples, PIB-Cl and their derivatives were easy to separate from each other with methanol-water $(60: 40,70: 30,80: 20, \mathrm{v} / \mathrm{v})$ in $30 \mathrm{~min}$ because of few interference peaks. However, for real samples analysis the target peaks were partly overlapped with some unknown peaks when methanol-water $(60: 40,80: 20, \mathrm{v} / \mathrm{v})$ was used as the mobile phase. Methanol-water $(73: 27, \mathrm{v} / \mathrm{v})$ was found to be the optimum composition for the chromatographic separation with no overlapping peaks. Therefore, this composition was selected as the mobile phase for the determination of real samples. The typical chromatograms of fluorescent detection for standard, soil, crop and water samples are shown in Fig. 1.

\subsection{Performance of fluorescent detection}

Soil, crop and water samples were spiked with atrazine and simazine in order to determine the repeatability, precision and recovery. Several characteristics of the fluorescent method are given in Table 2.

The relative standard deviations (R.S.D.s) were $1.0 \sim 2.8 \%$. Recoveries of $84-95 \%$ were obtained for real samples. The R.S.D.s for water samples were smaller than in soil and crop samples. The recoveries in water samples were higher than in soil and crop samples probably because crop texture and soil granular had strong absorption sites. The regression equations of peak height $(\mathrm{cm})$ and injection concentration $(\mu \mathrm{g} / \mathrm{g})$ were determined with correlation coefficients of 0.999 . According to the extraction ratio in pre-treatment, when the signal-to-noise ratio $(S / N)$ was 2 , detection limits of $1.2 \mathrm{ng} / \mathrm{g}$ for atrazine and $1.1 \mathrm{ng} / \mathrm{g}$ for simazine could be obtained.

On the basis of the good repeatability, low detection limits and high recoveries, the residues of atrazine and simazine in environmental samples can be analyzed in this method quantitatively.

\subsection{Comparison of $L C-F L$ and $G C-M S$ data}

In order to examine the reliability of the off-line pre-column derivatization LC-FL procedure, five soil and five crop samples from an agricultural area (their composition are shown in Table 1) were analyzed by this procedure in our laboratory and simultaneously, by the conventional off-line extraction GC-MS procedure in another laboratory. The analytical data are shown in Table 3 .

The analytical results achieved by LC-FL were in good agreement with the results by GC-MS with a relative difference of $5-11 \%$. For soil and crop analysis the LC-FL procedure, i.e., extraction, concentration, derivatization and $\mathrm{LC}-\mathrm{FL}$, was less timeconsuming than the conventional GC-MS procedure, i.e., extraction, concentration, clean-up, second-time concentration and GC-MS, because the clean-up and second-time concentration process (about $100 \mathrm{~min}$ ) were replaced by a derivatization process (about 20 min).

Therefore, the off-line extraction derivatization LC-FL procedure was an alternative to the conventional off-line extraction GC-MS procedure.

\section{Conclusions}

The potential of the off-line extraction pre-column derivatization $\mathrm{LC}-\mathrm{FL}$ procedure was demonstrated by the successful analysis of soil, crop and water samples. Atrazine and simazine were used as model compounds for pesticides which contain $-\mathrm{NH}$ group(s) and do not possess fluorescence characteristic without derivatization. On the basis of the conventional sample pretreatment procedure, the cleanup and second-time concentration process were replaced by a derivatization process. The derivatives with strong fluorescence properties could be detected by the LC-FL system. Detection limits at the $\mathrm{ng} / \mathrm{g}$ level and recoveries in the range $84-95 \%$ for real samples can be obtained. The relativity of the derivatization LC-FL and conventional GC-MS procedures was indicated by the practical application to five soil and five crop samples. 

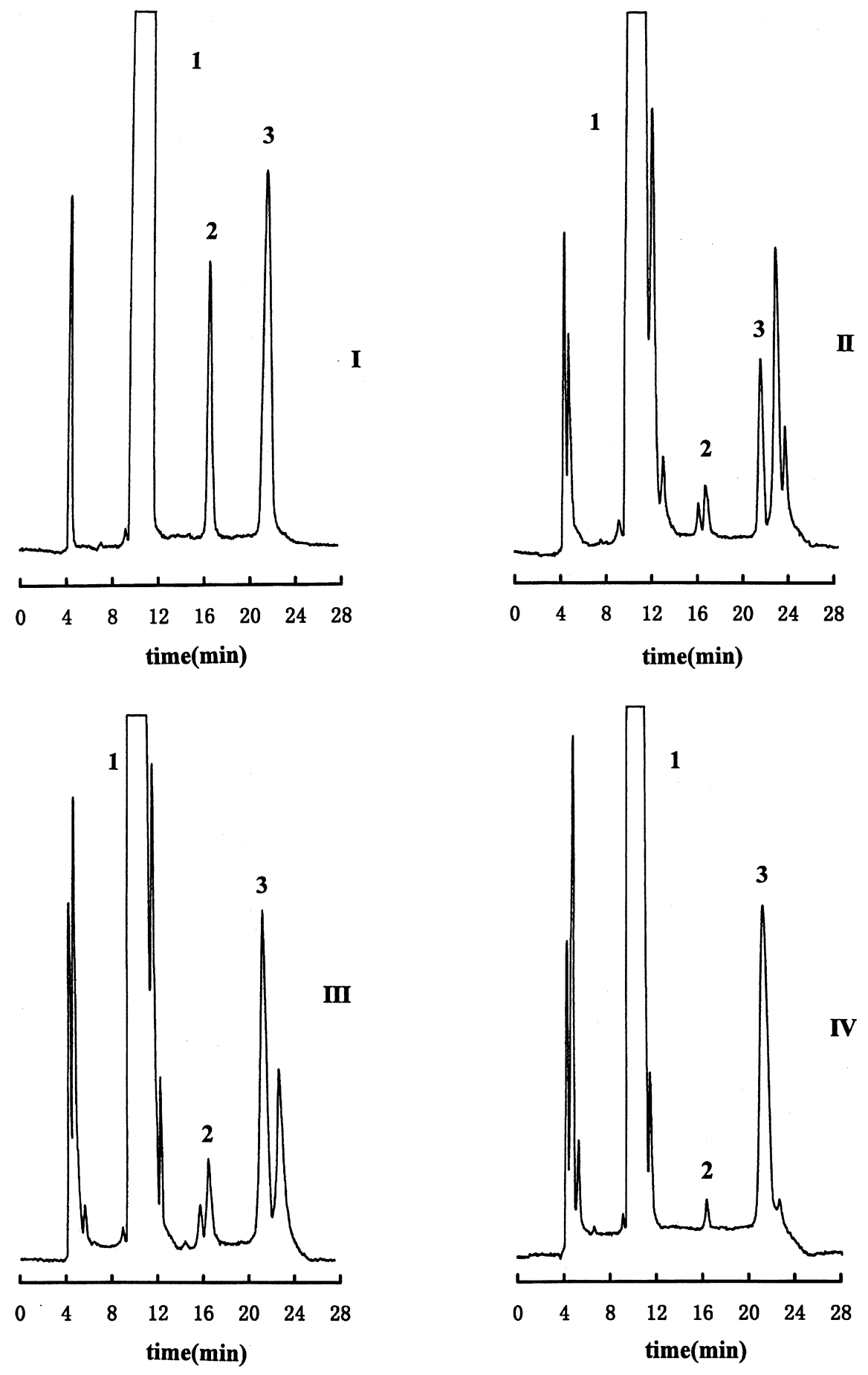

Fig. 1. The typical chromatograms of standard, soil, crop and water samples by the pre-column derivatization LC-FL procedure. I=Atrazine $(67 \mathrm{ng} / \mathrm{g})$ and simazine (33 ng/g) standard samples; II=soil sample (2); III=crop sample (3); IV=water sample. Mobile phase, methanol-water $(73: 27, \mathrm{v} / \mathrm{v})$; flow-rate, $0.8 \mathrm{ml} / \mathrm{min}$; FL detection at $312 \mathrm{~nm}$ excitation and $420 \mathrm{~nm}$ emission; Peaks: 1=PIB-Cl; $2=$ simazine derivative; $3=$ atrazine derivative. 
Table 2

Data for the atrazine and simazine in fluorescence detection

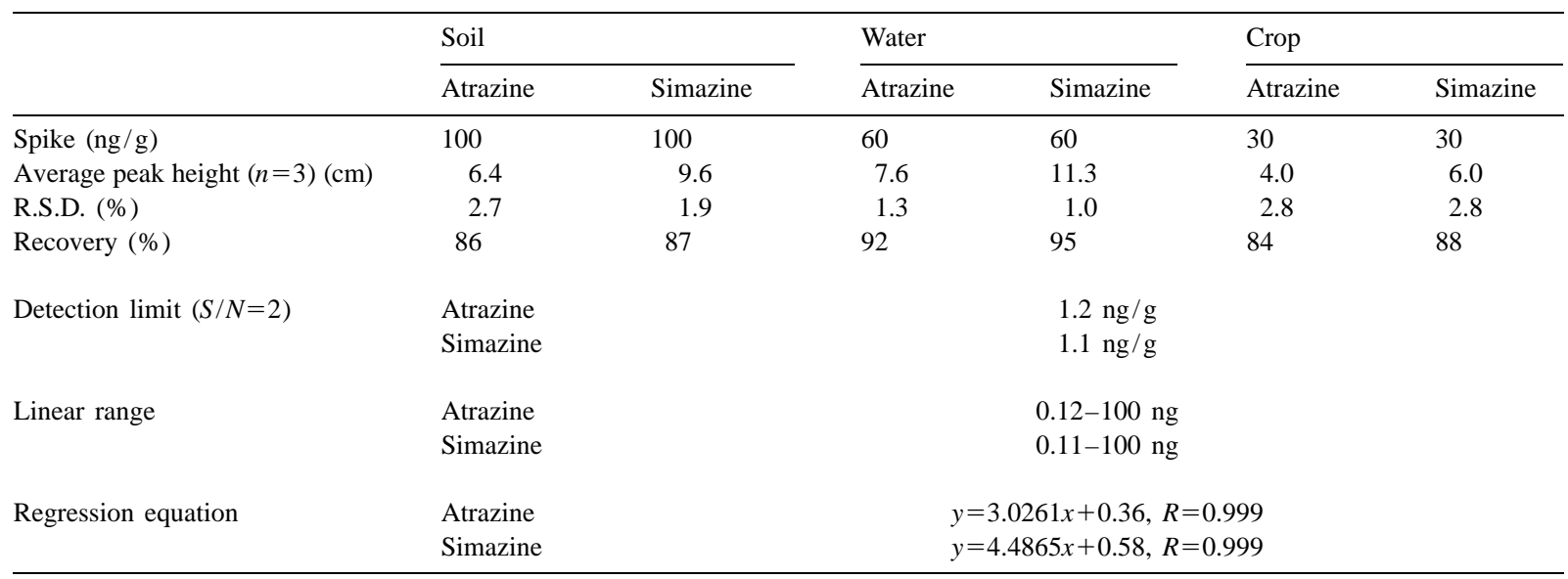

Table 3

Comparison between LC-FL and GC-MS procedures

\begin{tabular}{|c|c|c|c|c|c|c|c|c|c|c|}
\hline & \multicolumn{5}{|c|}{ Soil (ng/g) } & \multicolumn{5}{|c|}{ Crop (ng/g) } \\
\hline & 1 & 2 & 3 & 4 & 5 & 1 & 2 & 3 & 4 & 5 \\
\hline LC-FL & 21.9 & 61.8 & 31.2 & 51.0 & 40.8 & 95.2 & 125.1 & 116.3 & 83.4 & 94.5 \\
\hline GC-MS & 20.4 & 58.8 & 28.7 & 56.5 & 45.5 & 90.5 & 118.6 & 123.8 & 89.2 & 90.3 \\
\hline
\end{tabular}

However, there were two disadvantages for the LC-FL procedure. First, compared with the on-line SPE-GC-MS or NPD procedure, the off-line extraction LC-FL procedure was a relatively timeconsuming procedure for water sample analysis. Secondly, PIB-Cl was not commercially available.

In spite of some disadvantages, the off-line extraction LC-FL procedure, with its high sensitivity and selectivity, is the first-step in the search for automated on-line analysis for soil and crop samples. If fluorescence derivatization detection is connected with SPE, the detection limit can be decreased for water analysis. If fluorescence derivatization detection is combined with SFE, it may be possible to achieve a fast and sensitive technique for soil and crop analysis. If a new derivatization reagent which reacts with analytes rapidly is found, it is likely to accomplish an automated on-line analysis for soil and crop samples when connected with SFE or ultrasonic wave extraction.

\section{Acknowledgements}

The work was supported by the National Natural Science Foundation of China (29777026) and the Major Project Foundation of the Chinese Academy of Sciences (KZ951-B1-209-01).

\section{References}

[1] H.K. Lawrence, Compilation of EPA's Sampling and Analysis Methods, Lewis, Boca Raton, New York, 1996, CAS Nos. 1912-24-9, 122-34-9.

[2] D. Barcelo, M.-C. Hennion, Anal. Chim. Acta 338 (1997) 3-18.

[3] Th. Hankemeier, P.C. Steketee, J.J. Vreuls, U.A.Th. Brinkman, J. Chromatogr. A 750 (1996) 161-174.

[4] C. Aguilar, I. Ferrer, F. Borrull, R.M. Marcé, D. Barcelo, J. Chromatogr. A 794 (1998) 147-163.

[5] A.C. Hogenboom, W.M.A. Niessen, U.A.Th. Brinkman, J. Chromatogr. A 794 (1998) 201-210. 
[6] J.S. Salau, M. Honing, R. Tauler, D. Barcelo, J. Chromatogr. A 795 (1998) 3-12.

[7] S. Lacorte, J.J. Vreuls, J.S. Salau, F. Ventura, D. Barcelo, J. Chromatogr. A 795 (1998) 71-82.

[8] A.J.H. Louter, C.A. van Beekvelt, P. Cid Montanes, J. Slobodnik, J.J. Vreuls, U.A.Th. Brinkman, J. Chromatogr. A 725 (1996) 67-83.

[9] Th. Hankemeier, H.T.C. van der Laan, J.J. Vreuls, M.J. Vredenbregt, T. Visser, U.A.Th. Brinkman, J. Chromatogr. A 732 (1996) 75-84.

[10] R.J.C.A. Steen, I.L. Freriks, W.P. Cofino, U.A.Th. Brinkman, Anal. Chim. Acta 353 (1997) 153-163.

[11] V. Pichon, M. Charpak, M.-C. Hennion, J. Chromatogr. A 795 (1998) 83-92.
[12] B. Bjarni, B. Nikolas, E. Sergei, J. Gillis, Anal. Chim. Acta 347 (1997) 111-120.

[13] M. Winklmair, M.G. Weller, J. Mangler, B. Schlosshauer, R. Niessner, Fresenius J. Anal. Chem. 358 (1997) 614-622.

[14] J. Gascon, A. Oubina, I. Ferrer, P. Oennerfjord, G. MarkoVarga, B.D. Hammock, M. Marco, D. Barcelo, Anal. Chim. Acta 330 (1996) 41-51.

[15] V. Pichon, E. Aulard-Macler, H. Oubihi, P. Sassiat, M.-C. Hennion, M. Caude, Chromatographia 46 (1997) 529-536.

[16] Y. Tsuruta, K. Kohashi, Anal. Chim. Acta 192 (1987) 303313. 